\title{
Classification of follicular cell-derived thyroid cancer by global RNA profiling
}

\author{
Maria Rossing ${ }^{1,2}$ \\ ${ }^{1}$ Centre for Genomic Medicine, Rigshospitalet, Copenhagen University Hospital, Blegdamsvej 9, 2100 Copenhagen, \\ Denmark \\ ${ }^{2}$ Department of Endocrinology, Herlev University Hospital, Herlev, Denmark
}

Correspondence should be addressed to M Rossing

Email

maria.rossing@rh.regionh.dk

\begin{abstract}
The incidence of thyroid cancer is increasing worldwide and thyroid nodules are a frequent clinical finding. Diagnosing follicular cell-derived cancers is, however, challenging both histopathologically and especially cytopathologically. The advent of high-throughput molecular technologies has prompted many researchers to explore the transcriptome and, in recent years, also the miRNome in order to generate new molecular classifiers capable of classifying thyroid tumours more accurately than by conventional cytopathological and histopathological methods. This has led to a number of molecular classifiers that may differentiate malignant from benign thyroid nodules. Molecular classification models based on global RNA profiles from fine-needle aspirations are currently being evaluated; results are preliminary and lack validation in prospective clinical trials. There is no doubt that molecular classification will not only contribute to our biological insight but also improve clinical and pathological examinations, thus advancing thyroid tumour diagnosis and ultimately preventing superfluous surgery. This review evaluates the status of classification and biological insights gained from molecular profiling of follicular cell-derived thyroid cancers.
\end{abstract}
Key Words
- thyroid
- cancer
- classification
- global RNA profiling

Journal of Molecular Endocrinology (2013) 50, R39-R51

\section{Introduction}

Thyroid cancer is the most common cancer of the endocrine organs and its incidence has increased over recent decades (Kondo et al. 2006). The majority of thyroid carcinomas derive from follicular thyroid cells, also known as thyroid epithelium or thyroid principal cells, responsible for thyroid hormone production and secretion (Fig. 1). The follicular thyroid cell develops from an outgrowth of the pharyngeal endoderm in the region of the tongue (foramen caecum). Approximately 3\% of carcinomas are medullary carcinomas, which originate from parafollicular or C-cells that arise from the fourth branchial pouch and produce and secrete calcitonin.
The most common follicular cell-derived carcinomas are papillary thyroid carcinomas (PTCs), which account for 80-90\% of all thyroid cancers and have a 5-year survival above 90\% (Kondo et al. 2006). The second most common follicular cell-derived carcinomas are follicular thyroid carcinomas (FTCs), accounting for $\sim 10 \%$ of thyroid cancers (Kondo et al. 2006). The frequency of distant metastases at the time of diagnosis of FTC is up to $20 \%$. Nevertheless, the prognosis of FTC is still favourable with a 5-year survival close to 90\% (Kondo et al. 2006). FTCs are the malignant counterparts of benign follicular thyroid adenomas, which represent the most common follicular

Published by Bioscientifica Ltd. 


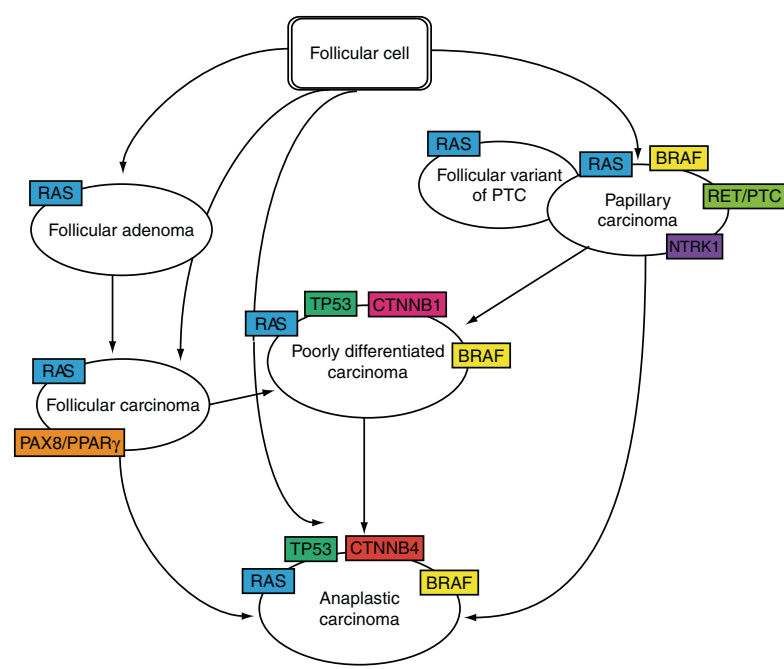

Figure 1

Schematic model of the stepwise dedifferentiation of follicular cell-derived thyroid cancer. Somatic mutations were depicted based on reported frequencies (Kondo et al. 2006, Nikiforov \& Nikiforova 2011).

cell-derived tumours of the thyroid (Faquin 2008). The sole morphological feature differentiating follicular thyroid adenomas from FTCs is the lack of invasion (capsular and/or vessel), invasion being the diagnostic criterion for FTCs (Faquin 2008). The diagnostic reproducibility of FTC is a challenge, and even among expert thyroid pathologists, the inter-observer and intra-observer reproducibility is low. One study found the agreement between five thyroid pathologists' initial diagnosis and the final consensus diagnosis of FTCs to be between 0.11 and 0.69 (Franc et al. 2003). Poorly differentiated and undifferentiated thyroid cancer, also known as anaplastic thyroid carcinoma (ATC), represents a small subset of follicular cell-derived cancers with a poor prognosis. The growth patterns of ATC and of poorly differentiated thyroid cancer are highly invasive and more than $50 \%$ of patients have distant metastases at the time of diagnosis (Kondo et al. 2006). The 5-year survival rate of ATC is no more than $5 \%$, illustrating why ATC is considered one of the most fatal human cancers (Kebebew et al. 2005).

Several somatic point mutations and chromosomal rearrangements have been identified in follicular cellderived thyroid cancer (see Fig. 1 for an overview). Mutations are present in genes belonging to the MAPK signalling pathway such as BRAF, HRAS, KRAS and NRAS as well as RET/PTC and TRK (NTRK1) fusion proteins (Nikiforov 2011).

Thyroid fine-needle aspirate (FNA) is the key test in the preoperative evaluation of euthyroid patients with thyroid nodules (Gharib et al. 2010). The possible cytopathological diagnoses determined by FNA are benign, malignant, non-diagnostic and suspicious/ indeterminate cytology (follicular neoplasia; Yassa et al. 2007). The latter category of lesions represents one of the greatest challenges to the attending physician as well as researchers in the field of thyroid cancer.

Recent studies have evaluated the diagnostic contribution of preoperative mutational testing of FNA with indeterminate cytology (Moses et al. 2010, Ohori et al. 2010, Filicori et al. 2011, Nikiforov et al. 2011). A common finding was that testing for well-known somatic mutations improved the diagnostic value. As somatic mutations were, however, only present in fewer than half of the malignant cases, the overall ability to rule out malignancy was not satisfactory.

In recent years, several studies have employed gene expression profiling to characterise thyroid cancer. The focus has mainly been on the diagnostic dilemma of follicular cell-derived neoplasia and on various classification models, as well as on thyroid cancer carcinogenesis (Eszlinger et al. 2008). Moreover, studies of epigenetic regulation, centred on expression profiling of microRNAs (miRNAs of 21-25 nucleotides), have appeared (de la Chapelle \& Jazdzewski 2011). It is noteworthy that a recent cost-benefit analysis favoured the addition of molecular testing of follicular cell-derived thyroid neoplasia at the preoperative stage, as this would lead to a more effective clinical management of these patients (Li et al. 2011).

Studies of expression levels of mRNAs by microarray analysis have been the primary way to investigate the transcriptome. It was recently recognised that only a fifth of the transcriptome consists of protein-coding mRNA (Kapranov et al. 2007). Thus, a great part of the mammalian transcriptome comprises noncoding RNAs, that in addition to the well-known noncoding RNAs of ribosomal RNAs and miRNAs, also comprise longnoncoding RNAs (>200 nucleotides). Future studies are likely to clarify the transforming potential of long noncoding RNAs as well as their value in thyroid cancer classification. This review focuses on the advantages of the addition of high-throughput technologies for transcriptional analyses with regard to tumour classification and the elucidation of thyroid carcinogenesis.

\section{Tumour biology of thyroid cancer as examined by microarray mRNA profiling}

Global mRNA microarray analysis is an efficient way of attaining a general idea of the genetic profiles of specific cancers. The following review of thyroid cancer profiling

Published by Bioscientifica Ltd. 
reveals that a unique genetic profile of each of the many pathohistological variants of follicular cell-derived thyroid cancer has not been established. This could be due to an inherent morphological heterogeneity as well as different time points for surgery of these relatively slow-growing cancers. Figure 2 illustrates the variance across 92 different thyroid samples based on the entire transcriptome depicted in a principal component analysis plot. In short, FTCs, follicular adenomas (FAs), fetal adenomas (FEAs) and PTCs do not form separate clusters but appear to be mingled together in a large group with little variance. Only the two extremes, represented by the ATCs and the hyperplastic nodules (HYPs)/nodular goitres, are clustered in well-defined groups. This plot illustrates the difficulties in obtaining a clear mRNA profile from each follicular cellderived thyroid tumour variant. Some of these difficulties might have a technical origin: differences in RNA extraction methods, tissue types and platform design may affect the final genetic profile. This is also evidenced by the poorer performances of molecular classifiers based

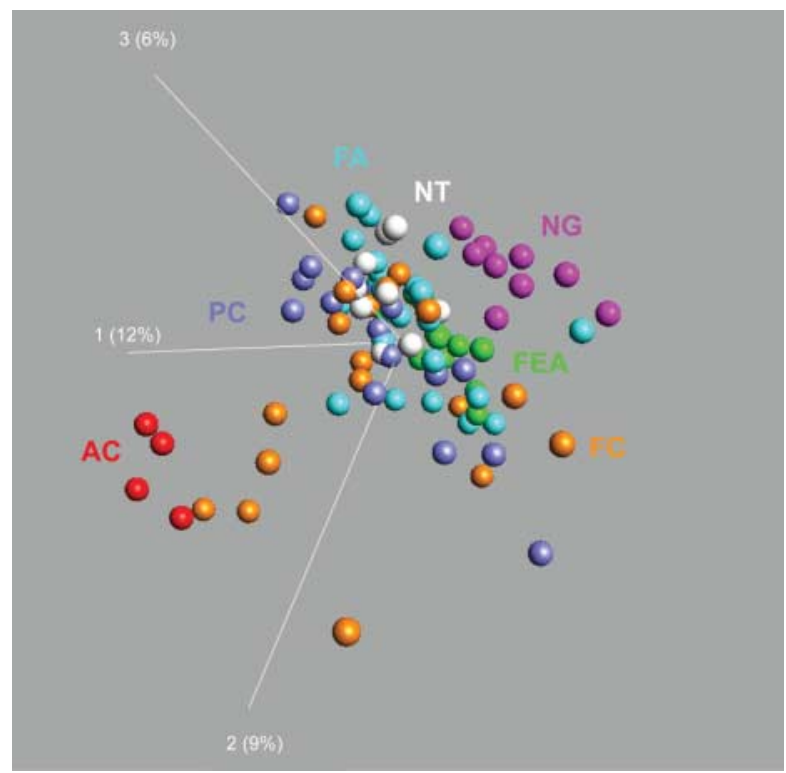

\section{Figure 2}

A principal component analysis based on the entire transcriptome from 92 different thyroid samples. The three first principal components are designated with the numbers 1-3. The percentage of the total variance described by each of the three principal components is given in parentheses at each axis. FA, light blue; follicular carcinoma (FC), orange; FEA, green; anaplastic carcinoma (AC), red; papillary carcinoma (PC), dark blue; nodular goitre (NG), pink; normal thyroid (NT), white. Adapted from Borup R, Rossing M, Henao R, Yamamoto Y, Krogdahl A, Godballe C, Winther O, Kiss K, Christensen L, Hogdall E, et al. 2010 Molecular signatures of thyroid follicular neoplasia. Endocrine-Related Cancer 17 691-708, 2010 with permission from Society for Endocrinology \& BioScientifica Ltd. on frozen tissue and subsequent validation with FNAs where the pre-processing procedures are different.

To gain insight into the carcinogenic processes underlying follicular cell-derived thyroid cancer, several studies have taken advantage of global RNA analyses. In particular, the use of microarray has been widespread; this, in short, consists of hybridisation of labelled RNA to an array of immobilised, complementary probes. The highthroughput array technique detects differences in expression levels of most of the transcriptome but lacks sufficient sensitivity for the detection of low abundance transcripts (Gupta et al. 2011). Several important transcripts encoding transcriptional regulators are expressed at low levels. Recent methodology, known as 'RNA-Seq', involves the conversion of RNA into cDNA with adaptors for deep-sequencing technology. RNA-Seq is highly sensitive and quantitative and is unbiased as it can quantify both known and unknown transcripts (Ozsolak $\&$ Milos 2011). This technique is likely to add to the present understanding of thyroid carcinogenesis.

The microarray study by Hawthorn et al. (2004) found the cellular adhesion genes TIMP1 (tissue inhibitor of metalloproteinase 1) and SERPINA1 to be up-regulated in PTC. SERPINA1 has recently been proposed as a consistent mRNA marker for PTC in a microarray meta-analysis of more than 40 PTC samples and 82 independent validation samples (Vierlinger et al. 2011). Moreover, this study showed the extracellular matrix pathway to be strongly activated, indicating an important role of tumour-stroma interaction in the carcinogenesis of PTC (Vierlinger et al. 2011). The performance of the diagnostic accuracy for PTC is specified in Table 1. Based on several online microarray results with relatively small sample sizes, another metaanalysis by Vizioli et al. (2010) recently confirmed downregulation of IGFBP7 in follicular cell-derived cancers (PTC and FTC). In addition, functional studies showed IGFBP7 to be an oncosuppressor with effects related to apoptosis. Thus, by taking advantage of larger microarray datasets accessible online, it is possible to strengthen the findings with functional studies.

Because the morphological features of PTC, FTC and follicular variant of PTC (FVPTC) are similar, mRNA profiling studies have been carried out to improve the understanding of the different molecular features of these cancers. Aldred et al. (2004) compared PTC and FTC profiles and found overexpression of CITED1, CLDN10 (encoding claudin 10 that plays a role in cell adhesion activity) and IGFBP6 (encoding insulin-like growth factorbinding protein 6 that alters the interaction of IGFs with their cell surface receptors) in PTC. Interestingly, CLDN10

Published by Bioscientifica Ltd. 
111111111

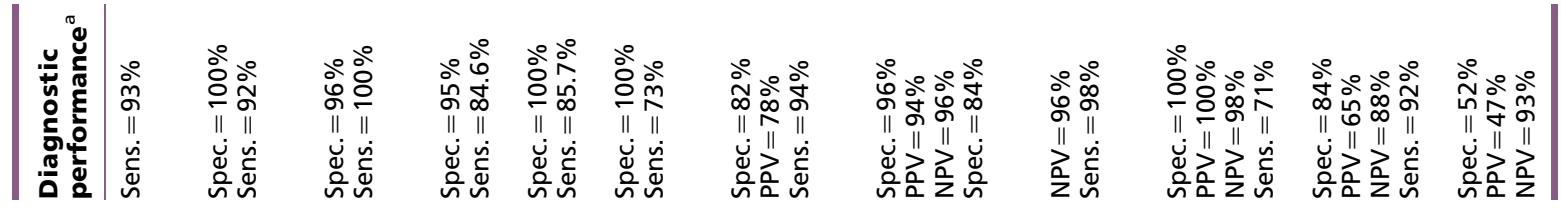

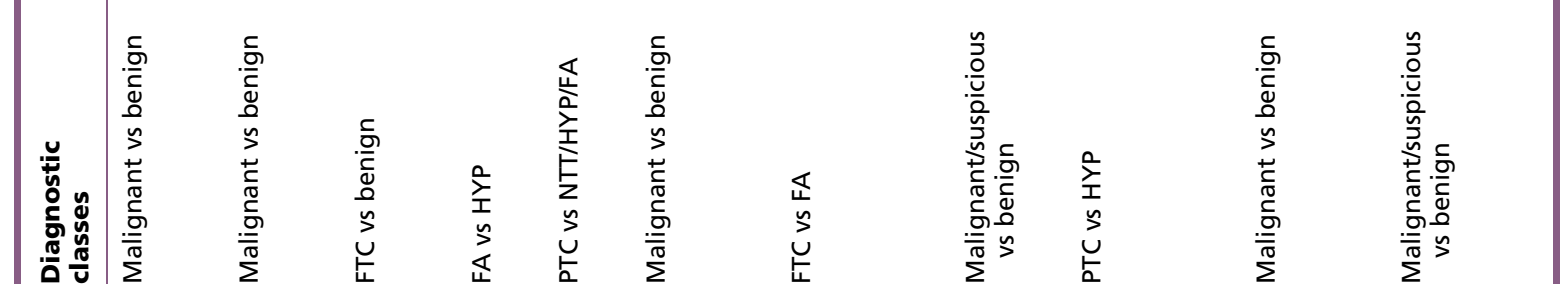
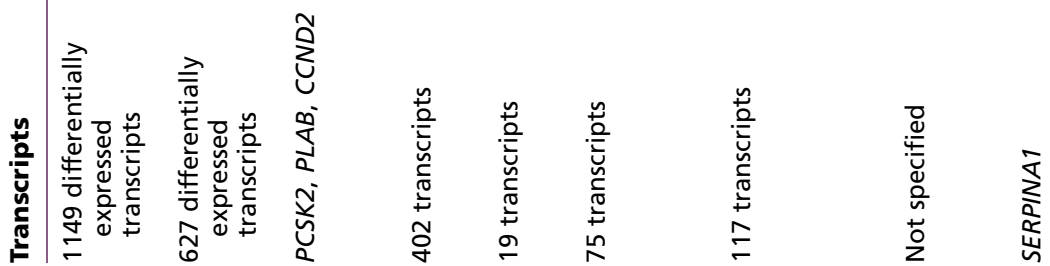

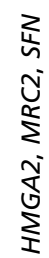
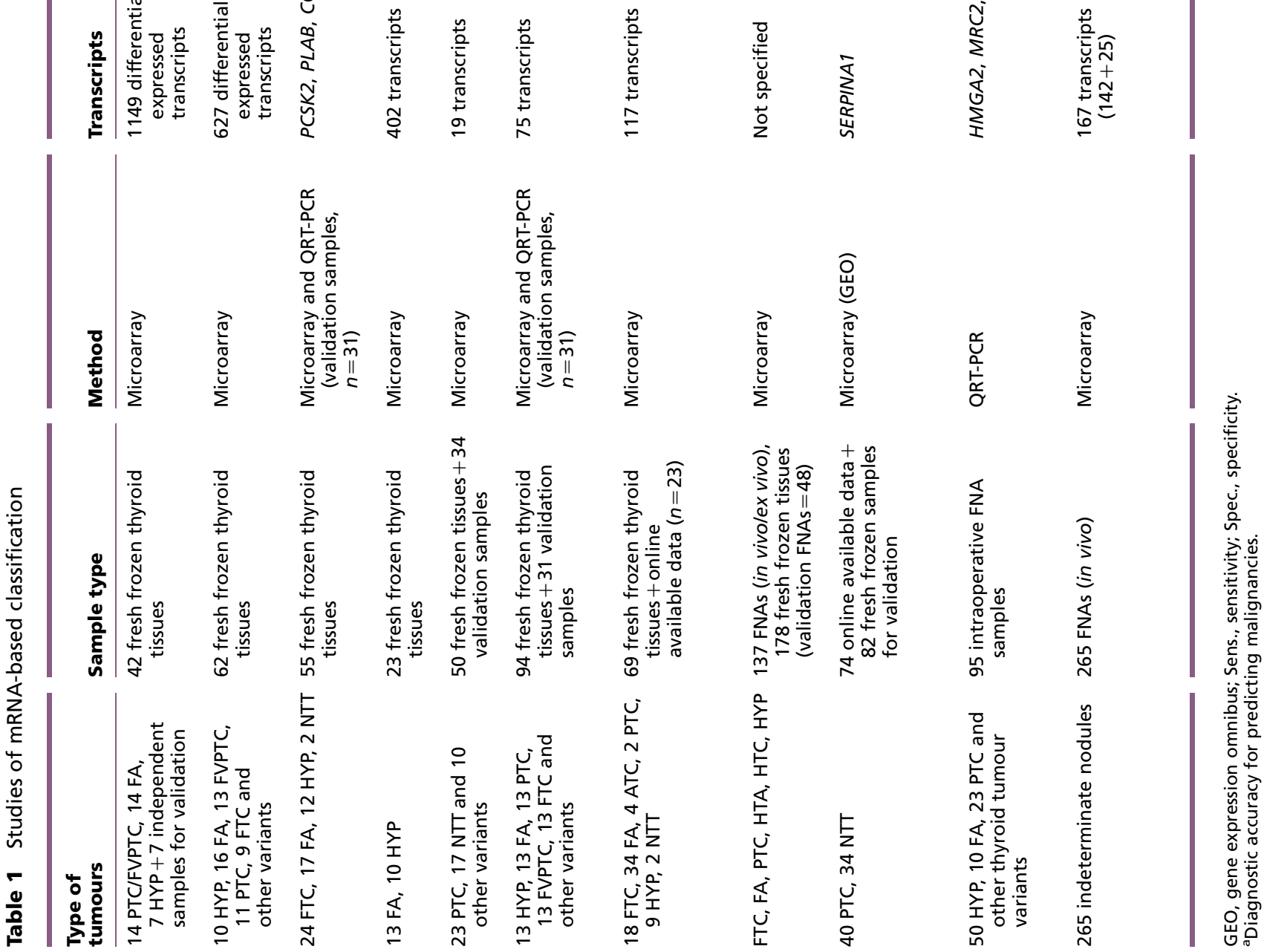
was completely absent in FTC, and IGFBP6, caveolin- 1 and caveolin-2 were down-regulated (Aldred et al. 2004). Caveolin-1 and -2 are co-expressed and encode proteins localised in caveolae as a part of the plasma membrane in most mammalian cells. Moreover, both genes may act as tumour suppressors. A subsequent study confirmed either a diverse molecular origin or a distinct genetic diversity from a common origin by identifying a number of differentially expressed transcripts in PTC vs FTC (cf. Fig. 2; Zhao et al. 2006).

One of the earliest microarray studies based on tissue samples from 19 FTCs and 14 adjacent normal thyroid tissues (NTTs) focused solely on the genetic signature of FTC and primarily identified loss of function; caveolin-1, caveolin-2, GDF10 (regulates differentiation), and glypican-3 (may regulate growth) were $\geq 15$-fold repressed in FTC. Subsequent immunohistochemical analysis of a large set of follicular cell-derived cancers indicated loss of caveolin-1 to be characteristic for FTC, thus representing a potential biomarker (Aldred et al. 2003). Furthermore, Chevillard et al. (2004) showed a similar diversity of involved biological functions in FTC and FA. They identified changes in expression levels for transcripts of gene families involved in the cytoskeleton, cell adhesion, cellular matrix, immune response and stress-related and signal transduction. Eszlinger et al. (2005) pooled expression profiles from HYP and FA and identified 31 differentially expressed transcripts after comparison with the adjacent NTTs. Gene set enrichment analysis showed a significant enrichment of cell cycle-associated genes (cyclin B, cyclin D, cyclin $\mathrm{H}, C D K 1$ and 7, p21, RB1, PRKDC, MAD2L1, CdC2O and WEE1, as well as transcription factors DP1 (TFDP1), E2F4 and E2F5) and G-protein kinase signalling. Moreover, Belge et al. (2008) showed an overexpression of HMGA2 in FTC as well as in PTC. The $H M G A 2$ transcript encodes a DNA-binding protein known to be an architectural factor in the DNA unwinding process. They evaluated the potential of $H M G A 2$ as a stand-alone biomarker. Based on RNA extraction from archived formalin-fixed, paraffin-embedded samples $(n=64)$ and subsequent QRT-PCR analysis, they determined a sensitivity and specificity for thyroid cancer of 96 and $94 \%$ respectively. In spite of these promising results, $H M G A 2$ is, however, not consistently up-regulated in FTCs, emphasising the need for a larger and more robust molecular classifier.

A later study conducted by our group not only classified but also characterised the expression profile of FTC. We showed FTC to be characterised by increased levels of mRNAs encoding proteins involved in DNA replication and mitosis, TOP2A, aniline (ANLN), PDZ-binding kinase $(P B K)$ and abnormal spindle-like microcephaly-associated protein (ASPM) (Borup et al. 2010). TOP2A is an enzyme that alters the topologic states of DNA in the transcription phase and its dysregulation can cause chromosomal instability. TOP2A is of particular interest as it represents a possible treatment target (Pritchard et al. 2008, O'Malley et al. 2009). Additionally, we found loss of transcripts encoding proteins involved in growth arrest and apoptosis such as FBJ murine osteosarcoma viral oncogene homologue B (FOSB), JUN proto-oncogene (JUN), NR4A1 and NR4A3 (nuclear receptor subfamily 4 , group $A$, member 1 and member 3 ) (Borup et al. 2010). Members of the orphan nuclear receptor family, NR4A1 and NR4A3, were studied both in vivo and in vitro by Mullican et al. (2007), who established their role as critical tumour suppressors in cancer. They showed that co-abrogation of NR4A1 and NR4A3 leads to acute myeloid leukaemia. A recent study by Lu et al. (2011) investigated the genes involved in the metastatic spread of thyroid carcinomas by generating a mouse that spontaneously develops metastatic FTC. By comparing the expression profiles of the tumour cells with hyperplastic thyroid cells from a wild-type mouse, the authors found more than a third of the 150 differentially expressed genes to be key regulators of metastasis, including olfactomedin 4 and epithelial membrane protein 2 . The remaining genes encoded proteins involved in metabolism, intracellular trafficking, transcription regulation, post-transcriptional modification and cell-cell signalling.

Only a few studies have explored the rare but virulent ATC by microarray analysis. Onda et al. (2004) showed up-regulation of GDI2 (localisation of Rab proteins), destrin (cell structure), HSPA8 (proliferation and apoptosis) and stathmin (microtubules) in anaplastic cell lines and primary ATCs and down-regulation of the thyroidspecific transcript thyroglobulin, as well as phosphatidylethanolamine-binding protein-1 and proto-oncogene c-FES (FES), genes indicating reversal to a poorly differentiated phenotype. To gain knowledge regarding thyroid carcinogenesis, Montero-Conde et al. (2008) examined seven ATCs, six poorly differentiated thyroid carcinomas, seven FTCs and 24 PTCs by microarray. Apart from confirming previously reported aberrantly expressed transcripts, they found an overexpression of key regulators (AKT2 (serine/threonine protein kinases), SOS1 (protooncogenic receptor tyrosine kinase) and FGFR1 (fibroblast growth factor receptor 1)) of the MAP kinase pathway as well as an under-expression of negative regulators (PLA2G6 (calcium-independent phospholipase A2),

Published by Bioscientifica Ltd. 
NF1 (neurofibromatosis-related protein NF-1) and CASP2 (caspase 2)) in poorly differentiated thyroid carcinoma/ATC vs well-differentiated cancers (FTC/PTC). Moreover, the study revealed overexpression of mRNAs encoding proteins involved in the cell cycle, focal adhesion, regulation of the actin cytoskeleton and the TGF- $\beta$ signalling pathway.

\section{Tumour biology of thyroid cancer as examined by global miRNA profiling}

miRNAs are noncoding and single-stranded RNAs of 21-25 nucleotides. miRNAs regulate translation and stability of about one third of the mammalian proteincoding mRNAs by imperfect base pairing to the $3^{\prime}$-ends of their target mRNAs (Bartel 2004, 2009, Friedman et al. 2009). The expression of miRNAs is temporally and spatially controlled and miRNAs exhibit important functions during developmental stages as well as in mature cells (Schmittgen 2008). Moreover, miRNAs are aberrantly expressed in a variety of cancers (Rosenfeld et al. 2008). Many target mRNAs encode oncogenic proteins and tumour suppressors and are susceptible to dysregulated miRNAs that may play a causal role in malignant progression. The library of human miRNAs contains $\sim 1000$ unique mature miRNAs, which, in contrast to the transcriptome, is a more manageable number of genes to investigate. miRNAs are well preserved in frozen specimens, FNAs and formalin-fixed, paraffin-embedded samples, establishing them as attractive molecular objects of study in translational medicine. However, as miRNAs are considered as modulators of the transcriptome rather than major switches of gene expression, it is necessary to relate the aberrant miRNAs with their target mRNAs in order to analyse their significance in any cancer.

In a recent review, de la Chapelle \& Jazdzewski (2011) proposed that the failure to find mutations in traditional protein-coding genes is not coincidental and hypothesised that changes in the expression of multiple noncoding RNA genes, e.g. miRNAs, might be an important mechanism in thyroid carcinogenesis. A very recent report by $\mathrm{Yu}$ et al. (2012) examined specific miRNAs in sera and thyroid tissues of patients with PTC or benign nodules. This was achieved by genome-wide sequencing of miRNAs, followed by QRT-PCR quantification. Serum let-7e, miR-151-5p and miR-222 were well correlated with clinicopathological variables such as nodal status and tumour size. Moreover, expression levels of miR-151-5p and miR-222 decreased after tumour excision. To the best of our knowledge, $\mathrm{Yu}$ et al. were the first to explore and report serum miRNA levels in thyroid cancer patients by RNA sequencing. Obviously, the diagnostic potential requires further validation; however, this approach bypasses all the operator-dependent challenges of obtaining a sufficient amount of RNA from a single in vivo ultrasound-guided FNA and could be the blueprint for future minimally invasive diagnostic miRNA studies.

Studies of miRNAs in FTC have been reported by a limited number of research groups. At an early stage, Weber et al. (2006) examined miRNAs from primary FTC $(n=23)$ and FA $(n=20)$ tissue samples with microarray analysis. They found that miR-192, miR-346, miR-328 and miR-197 were overexpressed by 1.3 - to 1.8 -fold in FTC compared with FA. Functional studies showed that miR346 and miR-197 induced proliferation in a non-thyroid cell line. Moreover, knockdown of miR-346 and miR-197 resulted in growth arrest in two follicular thyroid cancer cell lines but not in a papillary thyroid cancer cell line, indicating that miR-346 and miR-197 are specific in the pathogenesis of FTC. In addition, Nikiforova et al. (2008) examined nine FTCs and eight FAs using a RT-PCR miRNA panel consisting of 158 human miRNAs. They reported overexpression of miR-187, miR-181b, miR-182, miR-221, miR-222 and miR-96 in both FTC and oncocytic FTC in comparison to NTT, as well as overexpression of miR-181b, miR-339 and miR-224 in both conventional FA and oncocytic FA (Nikiforova et al. 2008). Both miR-200a and miR-181b were up-regulated in conventional FTC and FA. Comparison of the results of these two studies reveals very little conformity. This is not surprising given the studies used different quantification techniques (microarray vs RT-PCR) as well as different set-ups in the comparison of diagnostic groups (FTC/FA vs FTC/NTT).

A study conducted by our group analysed tissue samples from 12 FTCs, 12 FAs and ten NTTs using the Exiqon microarray platform containing probes for more than 800 human miRNAs. We confirmed some of the previously reported miRNAs as aberrantly expressed in FTC, namely up-regulation of miR-221, miR-222, miR-182 and miR-96 and also identified a number of miRNAs not previously identified in FTC (Rossing et al. 2012). A large portion of the down-regulated miRNAs was shared among the carcinomas and adenomas and the level of downregulation did not differ much between the two tumour classes, indicating that the miRNA expression level changes represent an early event in follicular cell malignant transformation. A clear gradual downregulation of miR-199b-5p was, however, detected from NTT over FA to FTC where it was completely absent. Moreover, functional analyses demonstrated miR-199b-5p

Published by Bioscientifica Ltd. 
as an anti-proliferative component in follicular thyroid neoplasia. The numerous down-regulated miRNAs in FTC were explored by weighted target analyses, revealing a significant predominance of target transcripts encoding tumourigenic factors. This finding was also in concert with the mRNA profiles of our earlier study, which showed a significant up-regulation of these miRNA target transcripts (Borup et al. 2010). Furthermore, gene set enrichment analysis of our target transcripts showed an overlap with 'Rodrigues Thyroid Carcinoma Anaplastic Cluster', indicating a gradual pathogenic transformation of FTC to ATC. This association between FTC and ATC was supported by common features of our miRNA profiles and those reported in ATC by Braun et al. (2010).

The miRNA profile of ATC was first reported by Visone et al. (2007a), who compared ten ATC tissue samples with their adjacent tissues. They showed a clear over-representation of decreased miRNAs such as miR-30d, miR-125b, miR-26a and miR-30a-5p. Additionally, no miRNAs were up-regulated greater than twofold; however, miR-222 was 1.98-fold up-regulated. Validation was performed and functional experiments identified miR-125b and miR-26a as important regulators of cellular growth. The aforementioned study by Braun et al. (2010) not only confirmed the high frequency of under-expressed miRNAs in ATC, but also found that the miR-200 and miR-30 families clearly distinguished ATCs from PTCs and FTCs. In addition, functional studies showed that both the miR-200 and miR-30 families could decrease invasion of ATC-derived cells and hence these families were classified as 'anti-invasive miRNAs'. A global miRNA profile based on the ARO cell line was established by Takakura et al. (2008), who reported up-regulation of the miR-17-92 cluster and demonstrated growth reduction by selective inhibition of miR-17-3p, miR-17-5p and miR19-a.

ATC is a rare cancer and the studies by Braun $e t$ al. and Visone et al. are the only studies exploring the global miRNA profile based on eight or more tissue samples. For the rare thyroid cancers, it may be beneficial to merge the microarray data across studies. Consequently, 'noise' from different tissue types, RNA extraction methods, microarray platforms and variation in different array batches would be minimised and the results would include only the most consistent of the aberrantly expressed miRNAs.

The important regulatory function of miR-221/-222 by direct targeting of the well-characterised p27(Kip1) tumour suppressor transcript in a papillary thyroid cancer cell line, as well as other cancer cell lines, has been established (Galardi et al. 2007, Visone et al. 2007b). Subsequently, miR-221/-222 have been suggested as a family of oncogenes, i.e. onco-miRNAs. It is likely that miR-221/-222 also function as oncogenes by decreasing p27 protein expression in FTC. Thus, a complete functional study in the relevant cell lines exploring this hypothesis requires to be conducted.

Nikiforova et al. (2008) reported a correlation between the miRNA expression pattern and thyroid cancer specimens with somatic mutations in BRAF, RET/PTC or PAX8/PPAR (PPARG) translocations. Their study identified five differentially expressed miRNAs - miR-146b, miR-155, miR-187, miR-221 and miR-222 - among the individual groups of mutations. This finding indicates that in addition to the marked changes in the miRNA expression profile between malignant and normal cells, the individual mutational status of the malignant cells is also of some significance. By using whole-genome sequencing of cancers, a recently launched database designated 'SomamiR' depicts somatic mutations located within miRNAs or their target sites (Bhattacharya et al. 2013). Somatic mutations that alter miRNA target sites have not yet been identified in follicular cell-derived thyroid cancer.

\section{Building of molecular classification models}

An approach for building and improving a molecular classification model based on tissue specimens from thyroid nodules starts with a set of good-quality RNA samples from snap-frozen tissue or FNA samples with concomitant histopathological diagnosis. Subsequent expression profiling employing high-throughput analysis is typically able to screen each sample for more than 50000 probes, including redundant ones. Statistical analysis includes Student's $t$-test (adjusted $P$ value to eliminate type 1 errors), probe ranking, model fitting and training by a suitable algorithm. It is noteworthy that discrimination is often obtained from the expression levels of only a small fraction (below a few per cent) of the number of transcripts analysed. Upon construction of an initial classifier from the expression profiles of the set of samples by the use of an appropriate algorithm, a validation of classifier performance is conducted by recording the diagnostic accuracy when applied to profiles from an independent set of samples (Simon 2003). It is possible to improve the original classifier by incorporation of additional samples. The classifier will of course be improved by increasing the number of samples as background noise will be reduced. Also, the histopathological diagnosis equal to the 'gold standard' can never be completely flawless and an increasing number of samples will minimise the noise from incorrectly

Published by Bioscientifica Ltd. 
classified samples. Recently, a large study has stressed the importance of using the same type of tissue samples for the initial classifier construction as only moderate diagnostic accuracy was encountered when applying a tissue sample-derived classifier to FNA samples, whereas the performance of a classifier based on FNAs was markedly better (see next section; Chudova et al. 2010).

\section{mRNA-based classification models}

One of the remaining major challenges in the assessment of thyroid nodules is the differentiation between follicular cell-derived thyroid cancers and hyperplastic benign nodules based on preoperative FNAs. The diagnostic criteria for FTC rely on the presence of capsular and/or vascular invasion of tumour cells and this cannot be assessed from a cytological smear. Despite a clear histopathological definition of the malignancies of a given follicular neoplasia, the morphological findings are similar in FTC and FA. The molecular factors that determine a possible step-by-step malignant transition are still unresolved. Consequently, several studies have focused on the molecular classification of thyroid cancer and the benign counterparts. The classification studies are summarised in Table 1 and selected articles are discussed below.

Thomas Fahey and his collaborators were one of the first research groups to turn to gene expression profiling in an attempt to overcome the deficiencies of single marker analysis (Barden et al. 2003, Finley et al. 2004a,b, 2005). The studies were based on mRNA microarray analysis from a relatively small number of well-characterised snapfrozen tissue samples from FTC (minimally and widely invasive), Hürtle cell thyroid carcinoma (HTC), FA, HYP, FVPTC and PTC. The data analysis identified differentially expressed transcripts between the malignant and the benign lesions by comparing PTC vs HYP, FTC vs FA, and a pool of follicular cell-derived cancers vs FA and HYP together. Subsequently, a diagnostic sensitivity and specificity for detecting malignancy were calculated, and, as shown in Table 1, all the diagnostic accuracies from these studies were high. However, differentially expressed transcripts used to distinguish the different diagnostic groups were not filtered for their ability to discriminate, thus resulting in a high number of transcripts. Based on mRNA expression profiles, Weber et al. (2005) set out to find the smallest number of genes that could reliably classify FTC from FA, not just in the original data set comprising 41 follicular neoplasia, but ultimately in the validation samples $(n=31)$. Following ranking of probes and testing of different combinations of gene sets, the study concluded that FTCs could be discriminated from FA with a sensitivity of $100 \%$ and a specificity of $94.7 \%$ by accessing the expression values of cyclin D2 (CCND2), protein convertase 2 (PCSK2) and prostate differentiation factor (PLAB/GDF15). CCND2 and PCSK2 were highly up-regulated in FTC vs FA, and PLAB was fivefold down-regulated. A report by Jarzab et al. (2005) was one of the first that addressed the diagnostic implications of gene expression profiles by developing a molecular classifier comprising 19 transcripts (DPP4, GJB3, ST14, SERPINA1, LRP4, MET, EVA1 (MPZL2), SPUVE (PRSS23), LGALS3, HBB, MRKN2, MRC2, IGSF1, KIAAO830 (ENDOD1), RXRG, P4HA2, CDH3, IL13RA1 and MTMR4). The biological relevance of the selected transcripts showed an over-representation of cell-cell adhesion genes, leading the authors to hypothesise that the cell adhesion genes could relate to the invasive and metastatic process of PTC. The classifier was based on the support vector machine algorithm, including leave-one-out cross-validation. The molecular signature of 19 transcripts could classify PTCs from benign nodules and NTT with a sensitivity and specificity of 85.7 and $100 \%$ respectively. Finally, Jarzab et al. tested the classifier on the available PTC gene expression profiles reported by Huang et al. (2001) and found that it was able to categorise NTT and PTC correctly. Eszlinger et al. (2006) contributed to this report by recommending the validation of every new molecular classifier across data sets derived from different array generations. A study by Prasad et al. (2008) investigated the potential of a molecular classifier for differentiating between malignant and benign thyroid nodules by including all the eight tumour subtypes that can be associated with suspicious cytology (HYP, FA, Hürtle cell adenoma, lymphatic nodules, PTC, FVPTC, FTC and Hürtle cell carcinoma) distributed over 94 fresh frozen tissue samples. Seventy-five transcripts were differentially expressed between the malignant and benign groups and using nearest-neighbour classification they obtained $73 \%$ sensitivity, an $82 \%$ specificity and a positive predicted value (PPV) of $78 \%$ for predicting malignancies. Validation of the expression levels of 12 genes (HMGA2, LRRK2, PLAG1, DPP4, CDH3, CEACAM6, PRSS3, SPOCK1, PDE5A, RAG2, AGTR1 and TPO5) selected based on their rank order and their apparent biological importance in tumour development and cancer progression were examined in an independent validation tumour set of 31 samples and the results were more or less consistent with the array data. No attempt to use this reduced gene set for classification was reported at that time. Nevertheless, a recent study from the same group explored the

Published by Bioscientifica Ltd 
diagnostic potential of a three-gene model; HMGA2, MRC2 (mannose receptor, C type 2) and SFN (stratifin) (Prasad et al. 2012). Based on QRT-PCR data from 95 intraoperative-collected FNAs, Prasad et al. (2012) reported the ability of this three-gene model to correctly diagnose a FNA as malignant with a sensitivity of $71 \%$, specificity of $84 \%$, PPV of $65 \%$ and a negative predicted value (NPV) of $88 \%$. The classification study performed by our group focused on developing a genetic signature that could distinguish between FTC and FA as well as FEA/microfollicular adenoma (Borup et al. 2010). Upon microarray analysis of 92 tissue samples (83 follicular cell-derived malignant and benign plus nine NTTs), the comparative analysis identified 117, 240 and 512 differentially expressed probe sets between FTC and FA, FEA and FA, and FTC and FEA. In each leave-one-out loop, probes were ranked as well as fitted by the support vector machine algorithm. Following this principle, three classifiers were generated. Furthermore, a predicted probability was assigned to each sample upon classification. The main classifier (classifier 1 consisting of 76 probe sets) was generated to separate FTC from FA and did so with high accuracy (sensitivity $=94.4 \%$, specificity $=95.5 \%$, $\mathrm{PPV}=94.4 \%$ and NPV $=95.5 \%$ ). Moreover, the robustness of the classifier was validated by employing publicly available data as well as cross-platform data. The classifier provided the ability to diagnose follicular nodules originating from different geographical locations and platforms with similar accuracy.

The large multicentre study by Chudova et al. (2010) built two diagnostic classifiers by implementing the support vector machine algorithm on a large set of fresh frozen tissue samples $(n=178)$ and in vivo and ex vivo FNAs $(n=137)$ and subsequently evaluating the performance in an independent set of FNAs $(n=48)$. Testing of the tissuetrained classifier on the independent FNAs showed a sensitivity and specificity of 92 and 58\% respectively for classifying malignancies. The relatively poor specificity could be due to fundamental differences in the biological or technical properties of tissue samples and FNAs. Thus, the classifier trained on the FNA samples diagnosed malignant tumours with a specificity of $84 \%$ and a NPV of $96 \%$. Furthermore, the study explored the impact of diluting the expression values of their signatures with benign tissue. In silico and in vitro studies showed that the derived classifier was able to classify malignancies in most cases in the presence of $80 \%$ benign background. The project has been ongoing and the classifier subsequently evaluated in a series of indeterminate FNAs obtained from 49 USA academic and community-based sites, with
Alexander et al. (2012) presenting its performance. The final classifier was based on 167 transcripts selected by their performance ranking in a run on 32 remaining samples after excluding 31 FNAs for various reasons. Subsequently, the selected transcripts were measured in 233 new samples remaining from 328 after similar exclusions, and classifier performance was tested. The combined set of 265 samples comprised a total of ten cases of FTC. Unfortunately, $14 \%$ of the tested samples with an acceptable RNA quality were excluded post-unblinding due to shipment deviation. In these final remaining samples, the classifier identified malignancy with a sensitivity and specificity of 92 and $52 \%$ respectively. This is not a sufficient specificity for decision making, i.e. malignant or benign, immediate surgery or follow-up. The NPV was 93\%, which is promising when the aim is to rule out malignancy. Moreover, the classifier showed high NPVs for selected subgroups of indeterminate nodules (95\% for atypical or follicular lesion of undetermined significance, 94\% for follicular neoplasm or lesion suggestive of follicular neoplasm and $85 \%$ for a suspicious cytological finding). The data indicate that by measuring the expression values of the 167 transcripts from a cytologically indeterminate FNA (based on a minimum of two needle insertions), it might be possible to consider a more conservative approach for patients with 'benign' as classifier result. The classifier consists of transcripts encoding proteins involved in a variety of cellular processes, the most frequent being related to energy metabolism, cell differentiation and cellular development, indicating shifts in energy-producing pathways, commonly observed in cancer cells and exemplified by the Warburg effect (Kim \& Dang 2006).

Concerning the classifier suggested by Alexander et al., a subsequent study authored by many of the same researchers tested the analytic performance of the classifier in diagnosing cytologically indeterminate FNAs (Walsh et al. 2012). No significant differences regarding sample preprocessing as well as diagnostic sensitivity and sensitivity of the classifier were found upon comparison of the results obtained in the two different studies. These results may also emphasise the importance of experienced operators when performing high-throughput molecular analyses.

Comparing the diagnostic performances in different studies addressing the main diagnostic challenge of follicular neoplasia, i.e. the discrimination between FTC and FA (Table 1), it appears that quantification of a relatively high number (greater than about 100) of transcripts is required to rule out malignancies with a high certainty (NPV>95\%). This may reflect the heterogeneous expression pattern characteristics of FTC.

Published by Bioscientifica Ltd. 


\section{miRNA-based classification models}

Mazeh et al. (2011) examined the expression levels of miR-21, miR-31, miR-146b, miR-187, miR-221 and miR-222 in ex vivo FNAs (FNA performed in the operating room after tumour resection) from PTCs $(n=20)$ and HYPs $(n=7)$. The evaluated miRNAs were known to be altered in PTC but their diagnostic potential had not been examined previously. The results showed that miR-146b, miR-221 and miR-222 could individually differentiate between PTC and HYP with NPVs $>70 \%$ as shown in Table 2 . The results did not comprise a merging of the expression levels of all the evaluated miRNAs, which may have improved the diagnostic potential. Along the same vein, a comprehensive study by Vriens et al. (2012) encompassing 95 tissue samples (12 FTCs, 15 FAs, 12 Hürtle cell adenomas, 12 Hürtle cell carcinomas, 8 PTCs, 4 ATCs, 12 FVPTCs, 13 HYPs and 7 NTTs) and more than 120 ex vivo FNAs identified several differentially expressed miRNAs by comparing the malignant and benign neoplasia

Table 2 Studies of miRNA-based classification
(miR-100, miR-125b, miR-138 and miR-768-3p were up-regulated in the malignant entities). Subsequent QRTPCR analysis of the specific miRNAs revealed miR-138 to be differentially expressed between benign and malignant FNAs $(P<0.001)$ and an ultimate diagnostic accuracy of $75 \%$ and NPV of $81 \%$.

The miRNA signatures for classification of follicular neoplasia developed in our own laboratory consisted of data derived from two global RNA platforms: a conventional spotted microarray platform (>800 annotated miRNAs plus $>400$ proprietary miR-E-Plus sequences) and newly developed Universal RT miRNA PCR panels I and II enabling profiling of 742 human miRNAs (Rossing et al. 2012). The microarray classifier comprised just two miRNAs, miR-1826 and miR-E-Plus-1078, and diagnosed FTC with a PPV and NPV of $83 \%$, whereas the QRT-PCR-derived classifier comprised 14 miRNAs and diagnosed FTC with a PPV of $100 \%$ and a NPV of $92 \%$. Recently, Shen et al. (2012) examined a panel of miRNAs by QRT-PCR in RNA extracted from archived FNA specimens

\begin{tabular}{|c|c|c|c|c|c|c|}
\hline $\begin{array}{l}\text { Type of } \\
\text { tumours }\end{array}$ & Sample type & Method & MicroRNA & $\begin{array}{l}\text { Diagnostic } \\
\text { classes }\end{array}$ & $\begin{array}{l}\text { Diagnostic } \\
\text { performance }^{a}\end{array}$ & References \\
\hline 20 PTC, 7 HYP & Ex vivo FNAs & QRT-PCR & $\begin{array}{c}\operatorname{miR}-21,-31,-146 b \\
-187,-221,-222\end{array}$ & PTC vs HYP & $\begin{array}{l}\text { miR-221: Sens. }=95 \% \\
\text { Spec. }=100 \% \\
\text { PPV }=100 \% \\
\text { NPV }=96 \%\end{array}$ & $\begin{array}{l}\text { Mazeh et al. } \\
\text { (2011) }\end{array}$ \\
\hline $\begin{array}{l}12 \text { FTC, } 12 \text { FA, } \\
10 \text { NTT }\end{array}$ & $\begin{array}{l}34 \text { fresh frozen } \\
\text { tissues }\end{array}$ & $\begin{array}{l}\text { Microarray } \\
\text { QRT-PCR } \\
\text { panel }\end{array}$ & $\begin{array}{l}\text { Microarray: miR-1826 } \\
\text { and miR-E-Plus-1078 } \\
\text { QRT-PCR panel: } \\
\text { miR-19a, -501-3p, } \\
-17,-335,-106 b \text {, } \\
-15 a,-16,-374 a, \\
-542-5 p,-503, \\
-320 a,-326, \\
-330-5 p, \text { let-7i }\end{array}$ & FTC vs FA & $\begin{array}{l}\text { Microarray: } \\
\quad \text { PPV }=83 \% \\
\text { NPV }=83 \% \\
\text { QRT-PCR panel: } \\
\text { PPV }=100 \% \\
\text { NPV }=92 \%\end{array}$ & $\begin{array}{l}\text { Rossing et al. } \\
\text { (2012) }\end{array}$ \\
\hline $\begin{array}{l}88 \text { malignant } \\
\text { (PTC, FTC, } \\
\text { FVPTC, ATC), } \\
40 \text { benign } \\
\text { (HYP, HTA, FA) }\end{array}$ & $\begin{array}{l}128 \text { archived } \\
\text { FNAs }\end{array}$ & QRT-PCR & $\begin{array}{l}\text { miR-146b, -221, }-187 \\
\quad-30 d\end{array}$ & $\begin{array}{l}\text { Malignant } \\
\text { vs benign }\end{array}$ & $\begin{array}{l}\text { Training set: } \\
\text { PPV }=98 \% \\
\text { NPV }=83 \% \\
\text { Validation set: } \\
\text { PPV }=89 \% \\
\text { NPV }=78 \% \\
\text { Undetermined/ } \\
\text { atypia cytology: } \\
\text { PPV }=64 \% \\
\text { NPV }=79 \%\end{array}$ & Shen et al. (2012) \\
\hline $\begin{array}{l}10 \text { FVPTC, } 35 \text { PTC, } \\
111 \text { benign } \\
\text { (HYP, HTA, FA) }\end{array}$ & $\begin{array}{l}95 \text { intraoperative } \\
\text { FNAs + validation } \\
\text { set }(n=59)\end{array}$ & QRT-PCR & miR-7 & $\begin{array}{l}\text { Malignant } \\
\text { vs benign }\end{array}$ & $\begin{array}{l}\text { Sens. }=100 \% \\
\text { Spec. }=29 \% \\
\text { PPV }=36 \% \\
\text { NPV }=100 \%\end{array}$ & $\begin{array}{l}\text { Kitano et al. } \\
\quad(2012)\end{array}$ \\
\hline
\end{tabular}

HTA, Hürtle cell thyroid adenoma; HA, Hürtle cell adenoma; Sens., sensitivity; Spec., specificity. ${ }^{a}$ Diagnostic accuracy for predicting malignancies.

http://jme.endocrinology-journals.org DOI: 10.1530/JME-12-0170
(C) 2013 Society for Endocrinology Printed in Great Britain
Published by Bioscientifica Ltd 
$(n=128)$ and by linear discriminant analysis established a four-miRNA signature for diagnosing FNA with undetermined cytology. As detailed in Table 2, the performance of the classifier in the undetermined FNA samples leaves room for further refinement. However, the comprehensive results of extracting miRNA from archived FNAs could prove to have a major impact on future thyroid FNA classification studies. Recently, Kitano et al. (2012) reported that miR-7 could be used as an adjunct marker for malignancy based on their QRT-PCR analysis of intraoperative FNAs. The study evaluated four different miRNAs, miR-7, miR-126, miR-374a and let-7g in the training set and found only miR-7 to be significantly downregulated in the malignant samples. Subsequently, the miR-7 expression level was used to diagnose malignancy in the validation set and achieved a good result regarding the ability to rule out malignancy (NPV $=100 \%)$. However, the PPV and specificity were low, emphasizing the need for a broader signature preferably comprising both up-regulated and down-regulated miRNAs.

\section{Final remarks}

The main focus of the studies analysing samples of follicular neoplasia has been classification of tumours with indeterminate cytology. However, a consistent molecular profile has not been established for FTC. This could be due to true biological heterogeneity and/or reflect the difficulties in diagnosing follicular neoplasia correctly. Identification of a molecular signature is indeed dependent on the correctness of the initial histopathological diagnoses of the tumour samples on which the classifier is built. The fact that the focus of the studies has been on the differentiation between FTC and FA may also have hindered the establishment of a possible consistent molecular profile of FTC. This is in contrast to the easier diagnosed PTC, where a more uniform molecular profile has been identified and shows, for example, overexpression of FN1, MET, CITED1, SERPINA1, miR-146b, miR-21, miR-221 and miR-222.

One way of achieving the inherent profile of follicular cell-derived cancers might be by performing a comprehensive study - a large number of fresh frozen FTC specimens, unambiguously classified and with known mutational status. To diminish the contamination of NTT, it may be beneficial to supplement the analyses with RNA extracted from well-defined laser-captured microdissected FTC tumour tissue. Laser capture microdissection has the capacity to collect representative mRNA patterns in cancer and normal cells, leaving all unwanted cells behind. In this way, it is possible to separate sets of cells from normal, precancerous and cancerous tissue and potentially obtain a more characteristic molecular profile for the heterogenic group of follicular neoplasia represented by FTC and FA diagnoses. This scenario may follow the procedure established by Leethanakul et al. (2000) concerning the application of laser capture microdissection to head and neck squamous cell carcinomas.

Furthermore, upcoming next-generation sequencingbased studies may identify new mutations characterizing the different variants of follicular cell-derived cancer. This technique examines mutational status at the level of both RNA and DNA, the latter being appealing as DNA is stable and can be easily obtained from FNAs in a clinical setting. Based on the recent progress in molecular diagnostic procedures and the advent of the next-generation sequencing technique, it seems realistic that molecular classification will improve the current evaluation of cold thyroid nodules in the near future.

Declaration of interest

The author declares that there is no conflict of interest that could be perceived as prejudicing the impartiality of the review reported.

\section{Funding}

This review did not receive any specific grant from any funding agency in the public, commercial or not-for-profit sector.

\section{Acknowledgements}

The author wishes to thank Dr Finn Noe Bennedbæk and Prof. Finn Cilius Nielsen for their critical reading of the manuscript.

\section{References}

Aldred MA, Ginn-Pease ME, Morrison CD, Popkie AP, Gimm O, Hoang-Vu C, Krause U, Dralle H, Jhiang SM, Plass C et al. 2003 Caveolin-1 and caveolin-2, together with three bone morphogenetic protein-related genes, may encode novel tumor suppressors downregulated in sporadic follicular thyroid carcinogenesis. Cancer Research 63 2864-2871.

Aldred MA, Huang Y, Liyanarachchi S, Pellegata NS, Gimm O, Jhiang S, Davuluri RV, de la Chapelle A \& Eng C 2004 Papillary and follicular thyroid carcinomas show distinctly different microarray expression profiles and can be distinguished by a minimum of five genes. Journal of Clinical Oncology 22 3531-3539. (doi:10.1200/JCO.2004.08.127)

Alexander EK, Kennedy GC, Baloch ZW, Cibas ES, Chudova D, Diggans J, Friedman L, Kloos RT, LiVolsi VA, Mandel SJ et al. 2012 Preoperative diagnosis of benign thyroid nodules with indeterminate cytology. New England Journal of Medicine 367 705-715. (doi:10.1056/ NEJMoa1203208)

Barden CB, Shister KW, Zhu B, Guiter G, Greenblatt DY, Zeiger MA \& Fahey TJ III 2003 Classification of follicular thyroid tumors by molecular signature: results of gene profiling. Clinical Cancer Research 9 1792-1800. 
Bartel DP 2004 MicroRNAs: genomics, biogenesis, mechanism, and function. Cell 116 281-297. (doi:10.1016/S0092-8674(04)00045-5)

Bartel DP 2009 MicroRNAs: target recognition and regulatory functions. Cell 136 215-233. (doi:10.1016/j.cell.2009.01.002)

Belge G, Meyer A, Klemke M, Burchardt K, Stern C, Wosniok W, Loeschke S \& Bullerdiek J 2008 Upregulation of HMGA2 in thyroid carcinomas: a novel molecular marker to distinguish between benign and malignant follicular neoplasias. Genes, Chromosomes \& Cancer 47 56-63. (doi:10.1002/gcc.20505)

Bhattacharya A, Ziebarth JD \& Cui Y 2013 SomamiR: a database for somatic mutations impacting microRNA function in cancer. Nucleic Acids Research 41 D977-D982. (doi:10.1093/nar/gks1138)

Borup R, Rossing M, Henao R, Yamamoto Y, Krogdahl A, Godballe C, Winther O, Kiss K, Christensen L, Hogdall E et al. 2010 Molecular signatures of thyroid follicular neoplasia. Endocrine-Related Cancer 17 691-708. (doi:10.1677/ERC-09-0288)

Braun J, Hoang-Vu C, Dralle H \& Huttelmaier S 2010 Downregulation of microRNAs directs the EMT and invasive potential of anaplastic thyroid carcinomas. Oncogene 29 4237-4244. (doi:10.1038/onc.2010.169)

Chevillard S, Ugolin N, Vielh P, Ory K, Levalois C, Elliott D, Clayman GL \& El-Naggar AK 2004 Gene expression profiling of differentiated thyroid neoplasms: diagnostic and clinical implications. Clinical Cancer Research 10 6586-6597. (doi:10.1158/1078-0432.CCR-04-0053)

Chudova D, Wilde JI, Wang ET, Wang H, Rabbee N, Egidio CM, Reynolds J, Tom E, Pagan M, Rigl CT et al. 2010 Molecular classification of thyroid nodules using high-dimensionality genomic data. Journal of Clinical Endocrinology and Metabolism 95 5296-5304. (doi:10.1210/jc.2010-1087)

de la Chapelle A \& Jazdzewski K 2011 MicroRNAs in thyroid cancer. Journal of Clinical Endocrinology and Metabolism 96 3326-3336. (doi:10.1210/jc.2011-1004)

Eszlinger M, Krohn K, Berger K, Lauter J, Kropf S, Beck M, Fuhrer D \& Paschke R 2005 Gene expression analysis reveals evidence for increased expression of cell cycle-associated genes and Gq-protein-protein kinase C signaling in cold thyroid nodules. Journal of Clinical Endocrinology and Metabolism 90 1163-1170. (doi:10.1210/jc.2004-1242)

Eszlinger M, Wiench M, Jarzab B, Krohn K, Beck M, Lauter J, Gubala E, Fujarewicz K, Swierniak A \& Paschke R 2006 Meta- and reanalysis of gene expression profiles of hot and cold thyroid nodules and papillary thyroid carcinoma for gene groups. Journal of Clinical Endocrinology and Metabolism 91 1934-1942. (doi:10.1210/jc.2005-1620)

Eszlinger M, Krohn K, Hauptmann S, Dralle H, Giordano TJ \& Paschke R 2008 Perspectives for improved and more accurate classification of thyroid epithelial tumors. Journal of Clinical Endocrinology and Metabolism 93 3286-3294. (doi:10.1210/jc.2008-0201)

Faquin WC 2008 The thyroid gland: recurring problems in histologic and cytologic evaluation. Archives of Pathology \& Laboratory Medicine 132 622-632.

Filicori F, Keutgen XM, Buitrago D, AlDailami H, Crowley M, Fahey TJ III \& Zarnegar R 2011 Risk stratification of indeterminate thyroid fine-needle aspiration biopsy specimens based on mutation analysis. Surgery 150 1085-1091.

Finley DJ, Arora N, Zhu B, Gallagher L \& Fahey TJ III 2004a Molecular profiling distinguishes papillary carcinoma from benign thyroid nodules. Journal of Clinical Endocrinology and Metabolism 89 3214-3223. (doi:10.1210/jc.2003-031811)

Finley DJ, Zhu B, Barden CB \& Fahey TJ III $2004 b$ Discrimination of benign and malignant thyroid nodules by molecular profiling. Annals of Surgery 240 425-436. (doi:10.1097/01.sla.0000137128.64978.bc)

Finley DJ, Lubitz CC, Wei C, Zhu B \& Fahey TJ III 2005 Advancing the molecular diagnosis of thyroid nodules: defining benign lesions by molecular profiling. Thyroid 15 562-568. (doi:10.1089/thy.2005.15.562)

Franc B, de la Salmonière $\mathrm{P}$, Lange F, Hoang C, Louvel A, de Roquancourt A, Vilde F, Hejblum G, Chevret S \& Chastang C 2003 Interobserver and intraobserver reproducibility in the histopathology of follicular thyroid carcinoma. Human Pathology 34 1092-1100. (doi:10.1016/S00468177(03)00403-9)
Friedman RC, Farh KK, Burge CB \& Bartel DP 2009 Most mammalian mRNAs are conserved targets of microRNAs. Genome Research 19 92-105. (doi:10.1101/gr.082701.108)

GalardiS, Mercatelli N, Giorda E, MassaliniS, Frajese GV, CiafreSA\& Farace MG $2007 \mathrm{miR}-221$ and miR-222 expression affects the proliferation potential of human prostate carcinoma cell lines by targeting p27Kip1. Journal of Biological Chemistry 282 23716-23724. (doi:10.1074/jbc.M701805200)

Gharib H, Papini E, Paschke R, Duick DS, Valcavi R, Hegedus L \& Vitti P 2010 American Association of Clinical Endocrinologists, Associazione Medici Endocrinologi, and European Thyroid Association Medical Guidelines for clinical practice for the diagnosis and management of thyroid nodules. Journal of Endocrinological Investigation 33 1-50.

Gupta RK, Rosen ED \& Spiegelman BM 2011 Identifying novel transcriptional components controlling energy metabolism. Cell Metabolism 14 739-745. (doi:10.1016/j.cmet.2011.11.007)

Hawthorn L, Stein L, Varma R, Wiseman S, Loree T \& Tan D 2004 TIMP1 and SERPIN-A overexpression and TFF3 and CRABP1 underexpression as biomarkers for papillary thyroid carcinoma. Head \& Neck 26 1069-1083. (doi:10.1002/hed.20099)

Huang Y, Prasad M, Lemon WJ, Hampel H, Wright FA, Kornacker K, LiVolsi V, Frankel W, Kloos RT, Eng C et al. 2001 Gene expression in papillary thyroid carcinoma reveals highly consistent profiles. PNAS 98 15044-15049. (doi:10.1073/pnas.251547398)

Jarzab B, Wiench M, Fujarewicz K, Simek K, Jarzab M, Oczko-Wojciechowska M, Wloch J, Czarniecka A, Chmielik E, Lange D et al. 2005 Gene expression profile of papillary thyroid cancer: sources of variability and diagnostic implications. Cancer Research $\mathbf{6 5}$ 1587-1597. (doi:10.1158/0008-5472.CAN-04-3078)

Kapranov P, Cheng J, Dike S, Nix DA, Duttagupta R, Willingham AT, Stadler PF, Hertel J, Hackermuller J, Hofacker IL et al. 2007 RNA maps reveal new RNA classes and a possible function for pervasive transcription. Science 316 1484-1488. (doi:10.1126/science.1138341)

Kebebew E, Greenspan FS, Clark OH, Woeber KA \& McMillan A 2005 Anaplastic thyroid carcinoma. Treatment outcome and prognostic factors. Cancer 103 1330-1335. (doi:10.1002/cncr.20936)

Kim JW \& Dang CV 2006 Cancer's molecular sweet tooth and the Warburg effect. Cancer Research 66 8927-8930. (doi:10.1158/0008-5472.CAN-06-1501)

Kitano M, Rahbari R, Patterson EE, Steinberg SM, Prasad NB, Wang Y, Zeiger MA \& Kebebew E 2012 Evaluation of candidate diagnostic microRNAs in thyroid fine-needle aspiration biopsy samples. Thyroid 22 285-291. (doi:10.1089/thy.2011.0313)

Kondo T, Ezzat S \& Asa SL 2006 Pathogenetic mechanisms in thyroid follicular-cell neoplasia. Nature Reviews. Cancer 6 292-306. (doi:10.1038/nrc1836)

Leethanakul C, Patel V, Gillespie J, Pallente M, Ensley JF, Koontongkaew S, Liotta LA, Emmert-Buck M \& Gutkind JS 2000 Distinct pattern of expression of differentiation and growth-related genes in squamous cell carcinomas of the head and neck revealed by the use of laser capture microdissection and cDNA arrays. Oncogene 19 3220-3224. (doi:10.1038/sj.onc.1203703)

Li H, Robinson KA, Anton B, Saldanha IJ \& Ladenson PW 2011 Cost-effectiveness of a novel molecular test for cytologically indeterminate thyroid nodules. Journal of Clinical Endocrinology and Metabolism 96 E1719-E1726. (doi:10.1210/jc.2011-0459)

Lu C, Mishra A, Zhu YJ, Meltzer P \& Cheng SY 2011 Genomic profiling of genes contributing to metastasis in a mouse model of thyroid follicular carcinoma. American Journal of Cancer Research 1 1-13.

Mazeh H, Mizrahi I, Halle D, Ilyayev N, Stojadinovic A, Trink B, Mitrani-Rosenbaum S, Roistacher M, Ariel I, Eid A et al. 2011 Development of a microRNA-based molecular assay for the detection of papillary thyroid carcinoma in aspiration biopsy samples. Thyroid $\mathbf{2 1}$ 111-118. (doi:10.1089/thy.2010.0356)

Montero-Conde C, Martin-Campos JM, Lerma E, Gimenez G, Martinez-Guitarte JL, Combalia N, Montaner D, Matias-Guiu X, Dopazo J, de Leiva A et al. 2008 Molecular profiling related to poor prognosis in thyroid carcinoma. Combining gene expression data and 
biological information. Oncogene 27 1554-1561. (doi:10.1038/sj.onc. 1210792)

Moses W, Weng J, Sansano I, Peng M, Khanafshar E, Ljung BM, Duh QY, Clark OH \& Kebebew E 2010 Molecular testing for somatic mutations improves the accuracy of thyroid fine-needle aspiration biopsy. World Journal of Surgery 34 2589-2594. (doi:10.1007/s00268-010-0720-0)

Mullican SE, Zhang S, Konopleva M, Ruvolo V, Andreeff M, Milbrandt J \& Conneely OM 2007 Abrogation of nuclear receptors Nr4a3 and Nr4a1 leads to development of acute myeloid leukemia. Nature Medicine $\mathbf{1 3}$ 730-735. (doi:10.1038/nm1579)

Nikiforov YE 2011 Molecular analysis of thyroid tumors. Modern Pathology 24 (Suppl 2) S34-S43. (doi:10.1038/modpathol.2010.167)

Nikiforov YE \& Nikiforova MN 2011 Molecular genetics and diagnosis of thyroid cancer. Nature Reviews. Endocrinology 7 569-580. (doi:10.1038/ nrendo.2011.142)

Nikiforov YE, Ohori NP, Hodak SP, Carty SE, Lebeau SO, Ferris RL, Yip L, Seethala RR, Tublin ME, Stang MT et al. 2011 Impact of mutational testing on the diagnosis and management of patients with cytologically indeterminate thyroid nodules: a prospective analysis of 1056 FNA samples. Journal of Clinical Endocrinology and Metabolism 96 3390-3397. (doi:10.1210/jc.2011-1469)

Nikiforova MN, Tseng GC, Steward D, Diorio D \& Nikiforov YE 2008 MicroRNA expression profiling of thyroid tumors: biological significance and diagnostic utility. Journal of Clinical Endocrinology and Metabolism 93 1600-1608. (doi:10.1210/jc.2007-2696)

Ohori NP, Nikiforova MN, Schoedel KE, Lebeau SO, Hodak SP, Seethala RR, Carty SE, Ogilvie JB, Yip L \& Nikiforov YE 2010 Contribution of molecular testing to thyroid fine-needle aspiration cytology of "follicular lesion of undetermined significance/atypia of undetermined significance". Cancer Cytopathology 118 17-23. (doi:10.1002/cncy.20063)

O'Malley FP, Chia S, Tu D, Shepherd LE, Levine MN, Bramwell VH, Andrulis IL \& Pritchard KI 2009 Topoisomerase II alpha and responsiveness of breast cancer to adjuvant chemotherapy. Journal of the National Cancer Institute 101 644-650. (doi:10.1093/jnci/djp067)

Onda M, Emi M, Yoshida A, Miyamoto S, Akaishi J, Asaka S, Mizutani K, Shimizu K, Nagahama M, Ito K et al. 2004 Comprehensive gene expression profiling of anaplastic thyroid cancers with cDNA microarray of 25344 genes. Endocrine-Related Cancer 11 843-854. (doi:10.1677/erc.1.00818)

Ozsolak F \& Milos PM 2011 RNA sequencing: advances, challenges and opportunities. Nature Reviews. Genetics 12 87-98. (doi:10.1038/nrg2934)

Prasad NB, Somervell H, Tufano RP, Dackiw AP, Marohn MR, Califano JA, Wang Y, Westra WH, Clark DP, Umbricht CB et al. 2008 Identification of genes differentially expressed in benign versus malignant thyroid tumors. Clinical Cancer Research 14 3327-3337. (doi:10.1158/10780432.CCR-07-4495)

Prasad NB, Kowalski J, Tsai HL, Talbot K, Somervell H, Kouniavsky G, Wang Y, Dackiw AP, Westra WH, Clark DP et al. 2012 Three-gene molecular diagnostic model for thyroid cancer. Thyroid 22 275-284. (doi:10.1089/thy.2011.0169)

Pritchard KI, Messersmith H, Elavathil L, Trudeau M, O'Malley F \& Dhesy-Thind B 2008 HER-2 and topoisomerase II as predictors of response to chemotherapy. Journal of Clinical Oncology 26 736-744. (doi:10.1200/JCO.2007.15.4716)

Rosenfeld N, Aharonov R, Meiri E, Rosenwald S, Spector Y, Zepeniuk M, Benjamin H, Shabes N, Tabak S, Levy A et al. 2008 MicroRNAs accurately identify cancer tissue origin. Nature Biotechnology 26 462-469. (doi:10.1038/nbt1392)

Rossing M, Borup R, Henao R, Winther O, Vikesaa J, Niazi O, Godballe C, Krogdahl A, Glud M, Hjort-Sorensen C et al. 2012 Down-regulation of microRNAs controlling tumourigenic factors in follicular thyroid carcinoma. Journal of Molecular Endocrinology 48 11-23. (doi:10.1530/ JME-11-0039)

Schmittgen TD 2008 Regulation of microRNA processing in development, differentiation and cancer. Journal of Cellular and Molecular Medicine 12 1811-1819. (doi:10.1111/j.1582-4934.2008.00483.x)

Shen R, Liyanarachchi S, Li W, Wakely PE Jr, Saji M, Huang J, Nagy R, Farrell T, Ringel MD, de la Chapelle A et al. 2012 MicroRNA signature in thyroid fine needle aspiration cytology applied to "atypia of undetermined significance" cases. Thyroid 22 9-16. (doi:10.1089/thy.2011.0081)

Simon R 2003 Diagnostic and prognostic prediction using gene expression profiles in high-dimensional microarray data. British Journal of Cancer 89 1599-1604. (doi:10.1038/sj.bjc.6601326)

Takakura S, Mitsutake N, Nakashima M, Namba H, Saenko VA, Rogounovitch TI, Nakazawa Y, Hayashi T, Ohtsuru A \& Yamashita S 2008 Oncogenic role of miR-17-92 cluster in anaplastic thyroid cancer cells. Cancer Science 99 1147-1154. (doi:10.1111/j.1349-7006.2008.00800.x)

Vierlinger K, Mansfeld MH, Koperek O, Nohammer C, Kaserer K \& Leisch F 2011 Identification of SERPINA1 as single marker for papillary thyroid carcinoma through microarray meta analysis and quantification of its discriminatory power in independent validation. BMC Medical Genomics 4 30. (doi:10.1186/1755-8794-4-30)

Visone R, Pallante P, Vecchione A, Cirombella R, Ferracin M, Ferraro A, Volinia S, Coluzzi S, Leone V, Borbone E et al. 2007a Specific microRNAs are downregulated in human thyroid anaplastic carcinomas. Oncogene 26 7590-7595. (doi:10.1038/sj.onc.1210564)

Visone R, Russo L, Pallante P, De Martino I, Ferraro A, Leone V, Borbone E, Petrocca F, Alder H, Croce CM et al. 2007b MicroRNAs (miR)-221 and miR-222, both overexpressed in human thyroid papillary carcinomas, regulate p27Kip1 protein levels and cell cycle. Endocrine-Related Cancer 14 791-798. (doi:10.1677/ERC-07-0129)

Vizioli MG, Sensi M, Miranda C, Cleris L, Formelli F, Anania MC, Pierotti MA \& Greco A 2010 IGFBP7: an oncosuppressor gene in thyroid carcinogenesis. Oncogene 29 3835-3844. (doi:10.1038/onc.2010.136)

Vriens MR, Weng J, Suh I, Huynh N, Guerrero MA, Shen WT, Duh QY Clark OH \& Kebebew E 2012 MicroRNA expression profiling is a potential diagnostic tool for thyroid cancer. Cancer 118 3426-3432. (doi:10.1002/cncr.26587)

Walsh PS, Wilde JI, Tom EY, Reynolds JD, Chen DC, Chudova DI, Pagan M, Pankratz DG, Wong M, Veitch J et al. 2012 Analytical performance verification of a molecular diagnostic for cytology-indeterminate thyroid nodules. Journal of Clinical Endocrinology and Metabolism 97 E2297-E2306. (doi:10.1210/jc.2012-1923)

Weber F, Shen L, Aldred MA, Morrison CD, Frilling A, Saji M, Schuppert F, Broelsch CE, Ringel MD \& Eng C 2005 Genetic classification of benign and malignant thyroid follicular neoplasia based on a three-gene combination. Journal of Clinical Endocrinology and Metabolism 90 2512-2521. (doi:10.1210/jc.2004-2028)

Weber F, Teresi RE, Broelsch CE, Frilling A \& Eng C 2006 A limited set of human microRNA is deregulated in follicular thyroid carcinoma. Journal of Clinical Endocrinology and Metabolism 91 3584-3591. (doi:10.1210/jc.2006-0693)

Yassa L, Cibas ES, Benson CB, Frates MC, Doubilet PM, Gawande AA, Moore FD Jr, Kim BW, Nose V, Marqusee E et al. 2007 Long-term assessment of a multidisciplinary approach to thyroid nodule diagnostic evaluation. Cancer 111 508-516. (doi:10.1002/cncr.23116)

Yu S, Liu Y, Wang J, Guo Z, Zhang Q, Yu F, Zhang Y, Huang K, Li Y, Song E et al. 2012 Circulating microRNA profiles as potential biomarkers for diagnosis of papillary thyroid carcinoma. Journal of Clinical Endocrinology and Metabolism 97 2084-2092. (doi:10.1210/jc.2011-3059)

Zhao J, Leonard C, Brunner E, Gemsenjager E, Heitz PU \& Odermatt B 2006 Molecular characterization of well-differentiated human thyroid carcinomas by cDNA arrays. International Journal of Oncology 29 1041-1051.

Received in final form 21 January 2013

Accepted 25 January 2013

Accepted Preprint published online 25 January 2013 http://jme.endocrinology-journals.org

DOI: 10.1530/JME-12-0170
C 2013 Society for Endocrinology Printed in Great Britain 